\title{
Sphenoid Sinus Inverted Papilloma: A Case Report and Literature Review
}

\author{
Gustavo Figueiredo Nunes Rabelo ${ }^{1}$ Vinícius Antunes Freitas ${ }^{2}$ Bruno Hollanda Santos ${ }^{3}$ \\ Diego Costa de Souza Ferreira ${ }^{4}$ Ana Elisa Mota Silveira Magalhães ${ }^{1}$ Mírian Cabral Moreira de Castro ${ }^{5}$
}

1 ENT MR3, Otorhinolaryngology Department, Santa Casa de Belo Horizonte, Belo Horizonte, MG, Brazil

2 ENT, Head and Neck Surgeon, Otorhinolaryngology Department,

Santa Casa de Belo Horizonte, Belo Horizonte, MG, Brazil

3 Post graduation student, Otorhinolaryngology Department, IEP

Santa Casa de Belo Horizonte

${ }^{4}$ ENT MR2, Otorhinolaryngology Department, Santa Casa de Belo Horizonte, Belo Horizonte, MG, Brazil

${ }^{5} \mathrm{PhD}$; Head of the Otorhinolaryngology Department, Santa Casa de Belo Horizonte, Belo Horizonte, MG, Brazil
Address for correspondence Gustavo Figueiredo Nunes Rabelo, Av. Francisco Sales, $1111,4^{\circ}$ andar, Funcionários, Belo Horizonte, Minas Gerais, CEP: 30150-221, Brazil (e-mail: gusmed123@yahoo.com.br).

Int Arch Otorhinolaryngol 2014;18:332-335.

\begin{abstract}
\section{Keywords}

- inverted papilloma

- nasal cavity

- sphenoid sinus

Introduction Inverted papilloma is a rare benign tumor of the nasal fossa, which usually originates from its lateral wall. Only $5 \%$ of cases demonstrate exclusive sinus involvement. Primary sphenoid sinus involvement is even rarer. Although considered a benign lesion, the tumor has a potentially invasive nature and has also been found to have an associated malignancy rate of 7 to $15 \%$.

Objectives To report a case of inverted nasal papilloma originating in a rare location: the sphenoid sinus.

Resumed Report a 56-year-old woman, presented to our outpatient clinic complaining of frontal headache, occasional otalgia and recent forgetfulness. She was initially evaluated by a neurologist and then submitted to a head magnetic resonance imaging. A lesion was found to be filling both sphenoid sinuses. Sinus computed tomography showed an opacified sphenoid sinus with apparent bony integrity. The patient underwent sphenoidotomy through a transnasal endoscopic approach. A bleeding papillomatous lesion was identified. A biopsy was performed and histopathologic study suggested inverted papilloma. The lesion was then completely resected. The patient has been followed for 60 days after surgery; no signs of recurrence were found upon flexible nasofibroscope examination.

Conclusion Inverted Papilloma exclusively involving the sphenoid sinus is a rare entity. Non specific symptomatology and Clinical presentation make this kind of tumor a diagnostic and therapeutic challenge. The Endoscopic Sphenoidotomy has been the treatment of choice. Close follow-up is required in order to detect possible recurrences and malignant transformation.
\end{abstract}

received

June 9, 2013

accepted

December 2, 2013

published online

April 11, 2014
Copyright $(\underset{0}{ } 2014$ by Thieme Publicações License terms

Ltda, Rio de Janeiro, Brazil
DOI http://dx.doi.org/

10.1055/s-0034-1370761. ISSN 1809-9777.
(ब)(1) $\Theta$ 


\section{Introduction}

Inverted papilloma is a rare benign tumor of the nasal fossa, which usually originates from the lateral wall of the nasal cavity. Only $5 \%$ of cases have exclusive sinus involvement. Of the latter cases, the maxillary and ethmoid sinuses are most frequently affected. ${ }^{1}$ Primary sphenoid sinus involvement is rare. ${ }^{2-7}$ Although this tumor is considered a benign lesion, it has a potentially locally invasive nature, and it is correlated with bony erosion. It also has a tendency for local recurrence and an associated malignancy rate of 7 to $15 \%$, with squamous cell carcinoma being the most common histopathologic type. ${ }^{1,8}$

We report a case of inverted nasal papilloma originating in a very unusual location: the sphenoid sinus. We describe how the patient was managed, including detailed description of how the lesion was diagnosed and treated. We also report the therapeutic approach and results of 2-month follow-up.

\section{Literature Review}

Inverted papilloma is a rare benign sinonasal tumor, usually arising from the lateral aspect of nasal wall. It was first described in 1854 by Ward. ${ }^{9,10}$ It accounts for 0.5 to $4 \%$ of nasal tumors, and it is most often seen in the fifth and sixth decades of life. ${ }^{11}$ This tumor presents a characteristic endophytic growth pattern: its Schneiderian membrane inverts into the underlying stroma. ${ }^{8}$ It is also characterized by its potentially invasive nature; $70 \%$ of cases have been found to show evidence of bony erosion on computed tomography (CT) scan at diagnosis. It has high rates of recurrence, varying from 20 to $47 \%$ according to the current literature. ${ }^{12,13}$

The characteristic radiographic appearance of inverted papillomas is a unilateral polypoid lesion occupying the lateral nasal wall and paranasal sinuses. ${ }^{8}$ Only $5 \%$ of cases demonstrate exclusive sinus involvement, with the maxillary and ethmoid sinuses being the most commonly affected. ${ }^{8}$ Isolated inverted papilloma of the sphenoid sinus is rare. In a recent review of the English literature, 50 cases were reported. ${ }^{14}$ The majority of patients with inverted papilloma present with nasal complaints such as unilateral nasal obstruction, rhinorrhea, epistaxis, and so on. However, the clinical presentation of inverted papillomas confined to the sphenoid sinus is often nonspecific and insidious, with headache being the most common presentation. ${ }^{14}$

For years, the recommended treatment of choice consisted of medial maxillectomy and en bloc tumor excision through lateral rhinotomy or a midfacial degloving approach. Nevertheless, recently a more conservative management via a transnasal endoscopic approach has been advocated by some authors and has produced some good results. There has been a tendency to consider the exclusive endoscopic approach as the gold standard treatment for inverted papillomas, even in the more advanced stages of the disease and inclusive for the treatment of disease recurrences. ${ }^{15}$ This technique has remarkably improved throughout the years, presenting a decreased disease recurrence rate compared with the beginning of its use, and was the one chosen by us to

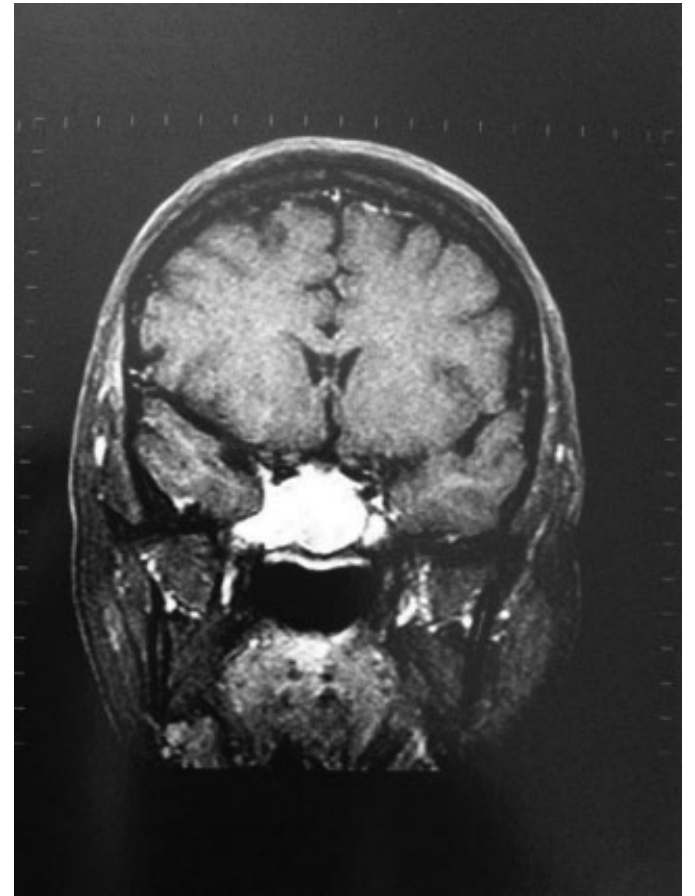

Fig. 1 Coronal view of head magnetic resonance image reveals a lobulated mass occupying both sphenoid sinuses enhanced by the contrast media with no unequivocal evidence of skull base involvement.

perform in our patient. ${ }^{16}$ The endoscopic technique has shown at least the same effectiveness as the external traditional approach, avoiding the comorbidities related to the latter one. ${ }^{17}$ Some advantages of this technique are better view of the surgical field, lesser resection of viable tissue, decreased nasal scabbing, and reduced amount of postoperative bleeding and pain.

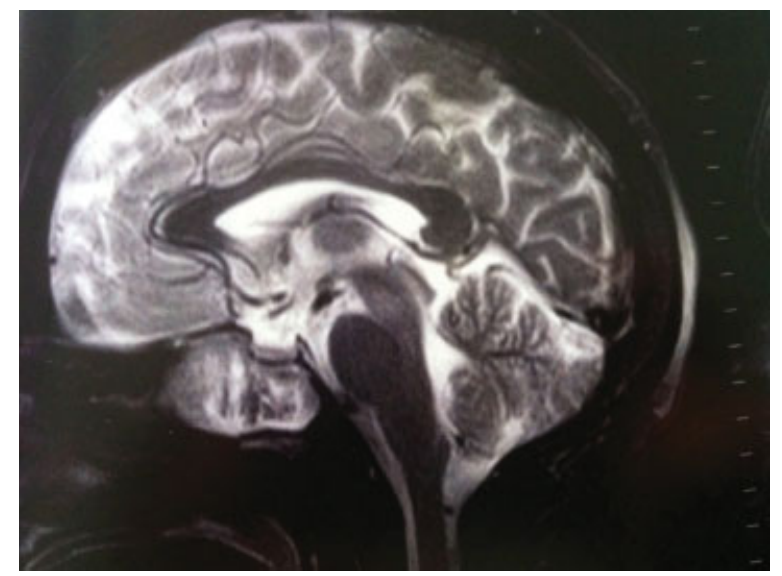

Fig. 2 Sagittal view of head magnetic resonance image shows evidence that the lesion might extend beyond the sphenoid sinus lateral wall toward the skull base, possibly affecting the cavernous sinus. 


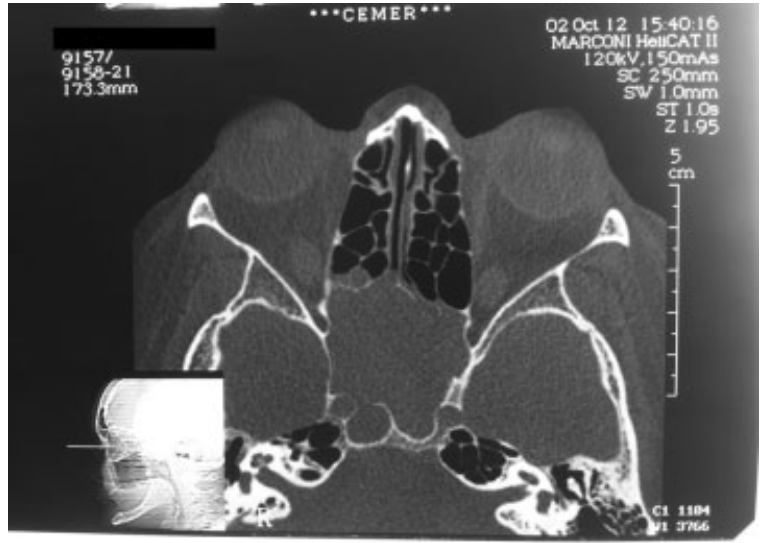

Fig. 3 Sinus computed tomography showing a soft tissue mass filling in the sphenoid sinus extending to the posterior sphenoid with apparent bony integrity.

\section{Case Report}

The patient, a 56-year-old woman, presented to our outpatient clinic with a 2-month history of frontal headache, occasional otalgia worsened when elevating the head, and recent forgetfulness. She was at first evaluated by a clinical neurologist and then submitted to a head magnetic resonance imaging (MRI) scan. A lesion was found filling and expanding both sphenoid sinuses, extending to the posterior ethmoidal cells and right sphenoethmoidal recess (-Figs. 1 and $\mathbf{2}$ ). The radiologist described it as a lobulated mass homogenously enhanced by the contrast media, which was hyperintensive on T2-weighted images and with intermediate intensity on T1-weighted images. The latter sequence also presented a tenuous hyperintensive signal on its inner part. Sinus CT showed an opacified sphenoid sinus with apparent bony integrity (-Fig. 3).

The patient underwent a sphenoidotomy through a transnasal endoscopic approach, by means of 0 - and 30-degree rigid fibroscopes. A bleeding papillomatous lesion was identified inside the sphenoid sinus. Biopsy was performed, and a fragment of tissue was sent for a frozen section analysis.

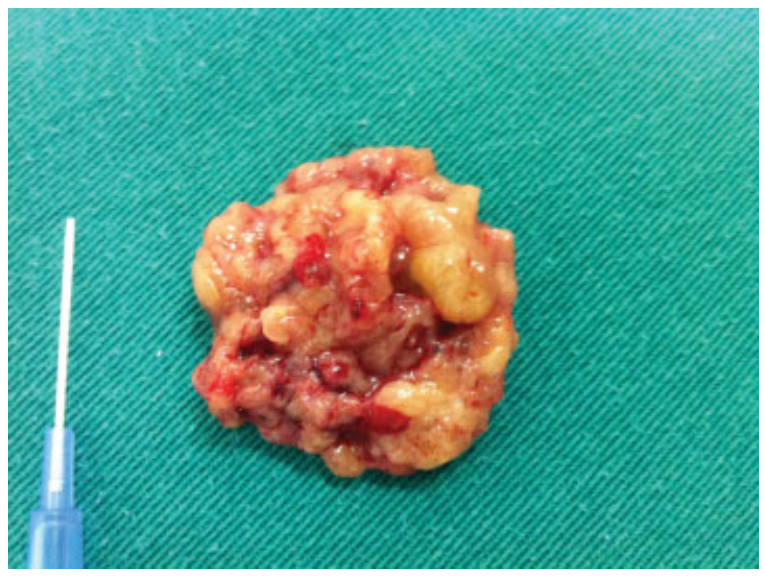

Fig. 4 Resected lesion.

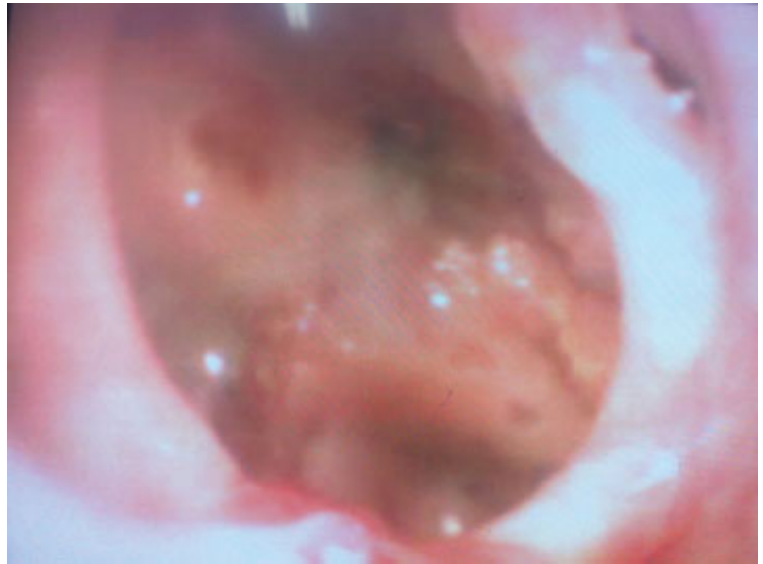

Fig. 5 Two-month postoperative nasofibroscopy.

Histopathologic study suggested inverted papilloma (-Fig. 4). The lesion was meticulously and completely resected through a bilateral sphenoid sinus endoscopic with deepithelialization. Postoperatively, the patient did well and was discharged the next day.

The patient has been followed in the head and neck outpatient clinic for 60 days after surgery, with no signs of recurrence found upon flexible nasofibroscope examination, as shown in the picture (-Fig. 5).

However, whether this single surgery will be sufficient therapy for our patient in the years to come remains to be seen. The literature describes most recurrences appearing between 1 and 11 months after the initial procedure. ${ }^{3}$ Although endoscopic sphenoidotomy appeared to be effective in this case, longer follow-up is necessary to determine whether the disease will recur. Therefore, regular and close follow-up is necessary in all cases following surgery to remove an inverted papilloma.

\section{Conclusions}

- Inverted papilloma exclusively involving the sphenoid sinus is a rare entity. Nonspecific symptomatology and clinical presentation make this kind of tumor a diagnostic and therapeutic challenge for otolaryngologists. Radiologic examinations, including MRI and CT scan, are particularly important to identify its characteristics. ${ }^{14}$ Endoscopic sphenoidotomy has been the treatment of choice; its effectiveness is described as at least equal to the traditional external approach although it is associated with less comorbidities. $^{18}$

- Close follow-up is required to detect possible recurrences and malignant transformation.

\section{References}

1 Phillips PP, Gustafson RO, Facer GW. The clinical behavior of inverting papilloma of the nose and paranasal sinuses: report of 
112 cases and review of the literature. Laryngoscope 1990;100(5): 463-469

2 Vogel K. Zur pathologischen anatomie des harten papilloms der nase. Beitr Pathol Anat 1926;23:117-123

3 Edison BD. Primary inverting papilloma of the sphenoid sinus. Trans Sect Otolaryngol Am Acad Ophthalmol Otolaryngol 1975; 80(5):434-437

4 McElveen JT Jr, Fee WE Jr. Inverting papilloma of the sphenoid sinus. Otolaryngol Head Neck Surg 1981;89(5):710-712

5 Sethi DS. Isolated sphenoid lesions: diagnosis and management. Otolaryngol Head Neck Surg 1999;120(5):730-736

6 Bielamowicz S, Calcaterra TC, Watson D. Inverting papilloma of the head and neck: the UCLA update. Otolaryngol Head Neck Surg 1993;109(1):71-76

7 Woodruff WW, Vrabec DP. Inverted papilloma of the nasal vault and paranasal sinuses: spectrum of CT findings. AJR Am J Roentgenol 1994;162(2):419-423

8 Clarke SR, Amedee RG. Schneiderian papilloma. J La State Med Soc 1997;149(9):310-315

9 Yiotakis I, Psarommatis I, Manolopoulos L, Ferekidis E, Adamopoulos G. Isolated inverted papilloma of the sphenoid sinus. J Laryngol Otol 2001;115(3):227-230

10 Azevedo CF, Lobato GL, Macoto KE. Evolution of endoscopic surgery in the treatment of inverted papilloma. Braz J Otorhinolaryngol 2013;79(1):13-17
11 Durucu C, Baglam T, Karatas E, Mumbuc S, Kanlikama M. Surgical treatment of inverted papilloma. J Craniofac Surg 2009;20(6): 1985-1988

12 Sadeghi N, Ao-Dhahri S, Manoukian JJ. Transnasal endoscopic medilal maxillectomy for inverting papilloma. Laryngoscope 2003;113(4):749-753

13 Kim WS, Hyun DW, Kim CH, Yoon JH. Treatment outcomes of sinonasal inverted papillomas according to surgical approaches. Acta Otolaryngol 2010;130(4):493-497

14 Guillemaud JP, Witterick IJ. Inverted papilloma of the sphenoid sinus: clinical presentation, management, and systematic review of the literature. Laryngoscope 2009;119(12): 2466-2471

15 Lian F, Juan H. Different endoscopic strategies in the management of recurrent sinonasal inverted papilloma. J Craniofac Surg 2012; 23(1):e44-e48

16 Krouse JH. Endoscopic treatment of inverted papilloma: safety and efficacy. Am J Otolaryngol 2001;22(2):87-99

17 Cannady SB, Batra PS, Sautter NB, Roh HJ, Citardi MJ. New staging system for sinonasal inverted papilloma in the endoscopic era. Laryngoscope 2007;117(7):1283-1287

18 Han JK, Smith TL, Loehrl T, Toohill RJ, Smith MM. An evolution in the management of sinonasal inverting papilloma. Laryngoscope 2001;111(8):1395-1400 